\title{
Solid Waste Composition and Management in Phu Huu Eco-Tourism Area, Hau Giang Province, Vietnam
}

\author{
Nguyen Thanh Giao
}

College of Environment and Natural Resources, Can Tho University, Vietnam

\begin{abstract}
The study was conducted to evaluate the current status of solid waste management in PhuHuu Eco-Tourism Area in HauGiang Province, Vietnam in 2019. The main research method was to interview managers and visitors to the place. In addition, the study also aimed to classify and estimate daily generated solid waste. The results presented that the rate of generation of solid waste was 0.3 $\mathrm{kg} /$ person/day, with total solid wastes of 70-100 kg/day for weekdays and 200-300 kg/day for weekends and holidays. The organic components accounted for 69\% including rice, leftovers, spoiled vegetables, fruit peels and leaves while inorganic components occupied $31 \%$ including plastic cups, straws, plastic wrap and foam boxes. Results of interviews with visitors indicated that the majority of tourists did not agree with the arrangement of rubbish bins and solid waste management in the tourist area. Solid waste management is not efficient due to the arrangement and the size of the waste bins, as well as the methods of solid waste classification. There is a need for better management of solid in the waste tourism area to attract more tourists to visit.
\end{abstract}

Keywords - Solid waste, inorganic components, organic components, PhuHuu eco-tourism area, HauGiang province.

\section{INTRODUCTION}

Tourism is an economic sector whose existence and development are associated with the ability to exploit resources and the characteristics of the surrounding environment. Therefore, tourism and environment have a very close relationship with each other and if inappropriate exploitation and development of tourism activities may cause depletion of resources, deterioration of environmental quality. According to the Vietnam Tourism Law (2005), ecotourism is a form of nature-based tourism, linked to the local cultural identity with community participation for sustainable development. Besides, the development of tourism activities generates waste. A combination of several studies shows that solid waste from tourism activities has a basic characteristic similar to the domestic waste of residential areas (Suarmatha, 1990; Jindal and Shikura, 1998). Some previous studies show that the average amount of bio-waste from tourists varies from 0.67 to $0.8 \mathrm{~kg} /$ person/day (Tran HieuNhue and Nguyen Quoc Cong, 2005). This can be considered as an important source of pollution from tourism activities, particularly in places where waste management and treatment are not yet appropriate.

PhuHuu eco-tourism area is located inPhuNghia hamlet, PhuHuu commune, Chau Thanh district, HauGiang province is a tourist destination with many specific characteristics. Thanks to the advantages of natural conditions and indigenous culture, PhuHuu today has become a familiar eco-tourism site not only for local tourists but also for visitors from other provinces. However, environmental protection issues such as solid waste management is the issues that need to be addressed to tourism management. The study was conducted to assess the rate of generation of solid waste and assess the current status of solid waste management including classification, collection, transportation and disposal of solid waste. The findings could provide important information on the waste generation rate and recommendation for better environmental protection in the tourism area. 


\section{MATERIALS AND METHODS}

\subsection{Introduction of PhuHuu eco-tourism}

PhuHuueco-tourismis located on Provincial Road 925, belonging to PhuNghia hamlet, PhuHuu commune, Chau Thanh district, HauGiang province. Being located on relatively flat plain, there are many ponds and ditches with an area of $11 \mathrm{ha}$. The tourist area includes food service areas, homestay resort services, sightseeing landscapes, playing service areas (including children's games, strongfeeling games, water games, terrestrial games, folk games ...), traditional craft villages, picnic camps, spiritual areas, aquaculture and garden canal systems fruit trees for tourism, buying and selling agricultural products and goods for tourists. PhuHuu eco-tourism officially put into operation on December 18, 2018.

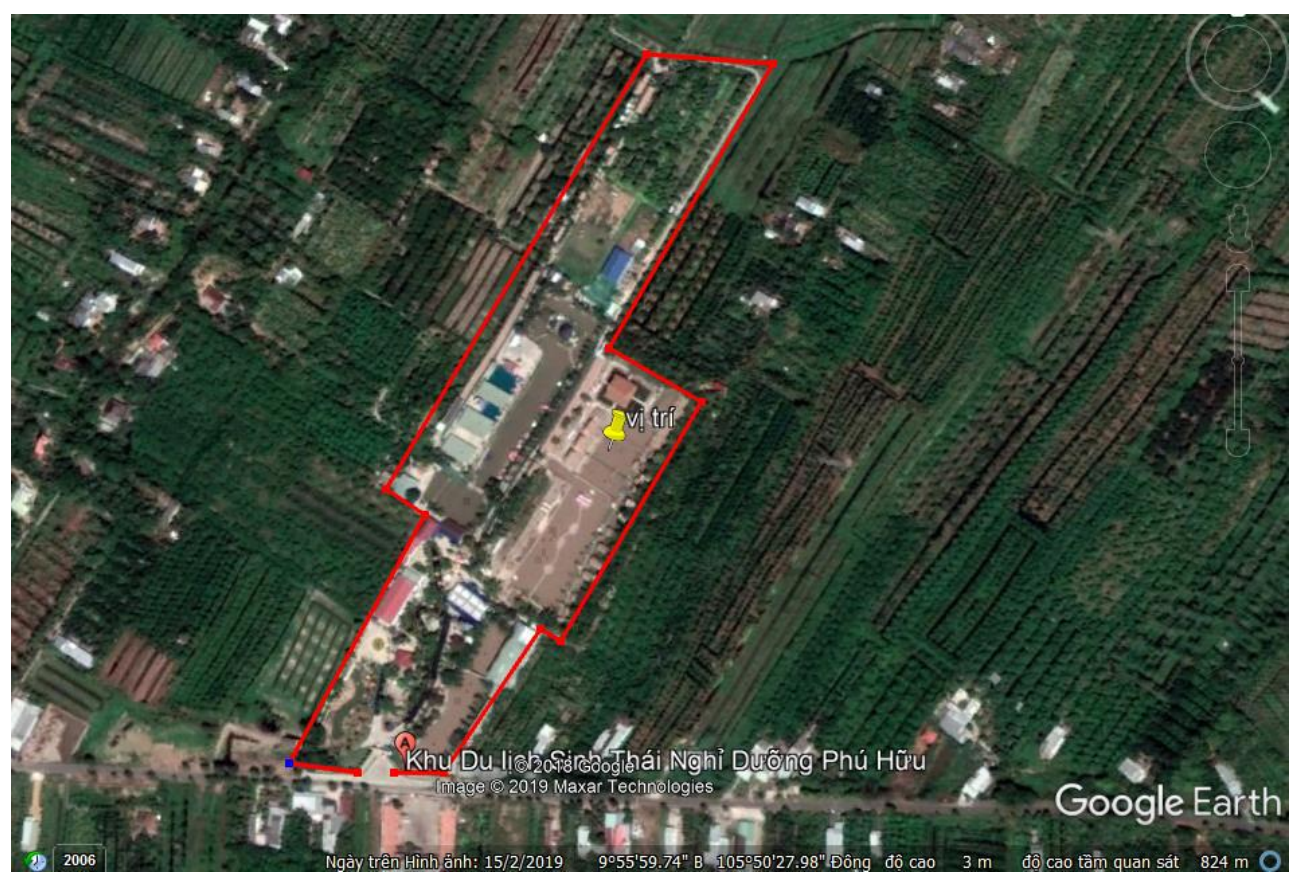

Fig.1: Location of PhuHuи ecotourism

\subsection{Data collection}

The study was conducted by interviewing 60 tourists and tourism management board to collect information including environmental management, application of legal documents, personnel arrangement and assessment, and evaluation of the interviewed tourists on the environmental management at the eco-tourism.

Based on the number of the locations of the waste binsin the tourist area, three waste bins was randomly selected at the end of the day, at 5 pmto detetermine the total weight and the waste composition. The composition of solid waste was obtained by the followingsteps: (1) Weigh the weight of the waste in the bin and then use the shovel to mix the wastes in the bin thoroughlt ; (2) Divide the wastes into four equal parts and take two opposite parts $(A+C)$ or $(B+D)$, then these two selected parts werewell mixed by shovel; (3) repeat the step (2); (4) the two opposite parts of the wastes in step 3 were collected for detemination of composition of solid waste. The wastes were then classified according to TCVN 6705: 2009 on ordinary solid waste-sorting. The collected data wasinput and processed by Microsoft Excel software presented mainly as percentages through simple charts and tables.

\section{RESULTS AND DISCUSSION}

\subsection{Sources of solid wastes}

In the tourist area, solid waste mainly comes from business activities such as counters for drinking water and fast food; restaurant area; fruit garden; area for organizing outdoor activities. The survey showed that visitors visited most areas in the tourism area; However, the drinking water area and the restaurant area were the two locations with relatively higher number of visitors. Therefore, these two locations can be assessed as the places where most solid waste is generated. In addition, the amount of solid waste that can originate from outside since the visitors prepared their own food, but the quantity could be very small.

\subsection{Solid waste composition}

Results of interviews from officials and employees of the tourist area indicated that the average 
number of tourists visiting the area is approximate 300-400 guests/day, and the number of visitors can be up to 9001000 guests/day on holidays and weekends. According to the report of the General Department of Environment (2008), the average rate of solid waste generation in the Mekong Delta region is $0.61 \mathrm{~kg} /$ person/day, if calculated according to this generation rate, the amount of waste at the study site is around $244 \mathrm{~kg} /$ day for normal days and $610 \mathrm{~kg} /$ day for holidays and weekends. Huong et al. (2018) and Long and Mai (2013) recorded at the tourist sites in HoaBinh and Binh Phuoc that the daily amount of solid waste was $201 \mathrm{~kg} /$ day and $261 \mathrm{~kg} / \mathrm{day}$; This difference could be explained due to the difference in the numbers of visitors.

The solid waste is measured by weighing the waste in three waste bins located at the stockpile (dimensions of each is $\varnothing 600 \mathrm{x} \mathrm{H} 470 \mathrm{~mm}$ ). The amount of solid wastes in the three waste bins (waste bin 1, 2, and 3) were $24 \mathrm{~kg}, 28.6 \mathrm{~kg}$ and $25.8 \mathrm{~kg}$, respectively. The solid waste composition was presented in Table 1. According to a report on solid waste management research in Vietnam, JICA (2011) classified solid waste into two categories including inorganicsolid wastes such as stone, gravel, cement, glass, nylon and organic solid wastes such as food waste, vegetable and fruit wastes, agricultural wastes.

Table 1. Composition of solid wastes in the waste bins

\begin{tabular}{|c|c|c|c|c|c|c|c|}
\hline \multirow{2}{*}{ No. } & & \multicolumn{3}{|c|}{ Organic solid wastes } & \multicolumn{3}{|c|}{ Inorganic solid wastes } \\
\hline & & Compostion & Weight & $\%$ & Compostion & Weight & $\%$ \\
\hline \multirow{3}{*}{1} & Waste bin 1 & \multirow{3}{*}{$\begin{array}{l}\text { Rice and } \\
\text { leftovers }\end{array}$} & 4.7 & 19.58 & \multirow{3}{*}{$\begin{array}{l}\text { Plastic cups } \\
\text { and wrap }\end{array}$} & 2.8 & 11.67 \\
\hline & Waste bin 2 & & 5.8 & 20.28 & & 4.2 & 14.69 \\
\hline & Waste bin 3 & & 6.1 & 23.64 & & 3.3 & 12.79 \\
\hline \multirow{3}{*}{2} & Waste bin 1 & & 5.2 & 21.67 & & 1.1 & 4.58 \\
\hline & Waste bin 2 & Vegetables & 6.2 & 21.68 & Plastic straws & 1.6 & 5.59 \\
\hline & Waste bin 3 & & 5.2 & 20.16 & & 1.5 & 5.81 \\
\hline \multirow{3}{*}{3} & Waste bin 1 & & 4.8 & 20 & & 2.2 & 9.17 \\
\hline & Waste bin 2 & Fruit wastes & 3.5 & 12.24 & Nylon & 1.9 & 6.64 \\
\hline & Waste bin 3 & & 3.9 & 15.12 & & 2 & 7.75 \\
\hline \multirow{3}{*}{4} & Waste bin 1 & & 2.3 & 9.58 & & 0.9 & 3.75 \\
\hline & Waste bin 2 & Leaves & 3.9 & 13.64 & Foam boxes & 1.5 & 5.24 \\
\hline & Waste bin 3 & & 2.6 & 10.08 & & 1.2 & 4.65 \\
\hline
\end{tabular}

In waste bin 1 , the major organic waste accounted for $70.83 \%$ of the total, with spoiled vegetables accounting for the highest of $5.2 \mathrm{~kg}(21.67 \%)$ and rice, uneaten food accounting for $19.58 \%$. For inorganic components, plastic cups accounted for the highest (about 11.67\%) compared to other similar components. The results of survey of waste bin 2 was similar to those recorded in waste bin 1, organic solid waste was approximate $19.4 \mathrm{~kg}$ (accounting for $67.83 \%)$ and inorganic solid waste took $32.17 \%(9.2 \mathrm{~kg})$. In waste bin 3, organic waste occupied a high proportion of $68.99 \%$ and very high inorganic waste took $12.79 \%$. This survey result was similar to that of Dieu et al. (2013) on household waste in Ho Chi Minh City with organic solid waste accounting for 80.1 - 90\%. In addition, Viet and Chiem (2013) also reported that the waste composition in the Mekong Delta is mainly composed of organic matters, accounting for $82.6 \%$. In addition, when compared with other province ( $\mathrm{Ca} \mathrm{Mau})$, the amount of solid waste generated an average of 1,028 tons/day (2014) with an organic content of $70-75 \%$ is also leftovers, vegetables and fruit peels (Ca Mau People's Committee, 2018). 
Table 2.The mean proportion of solid wastes compostition in the study area

\begin{tabular}{|c|c|c|c|c|c|c|}
\hline \multirow{2}{*}{ TT } & \multicolumn{3}{|c|}{$\begin{array}{c}\text { Organic solid wastes } \\
(18,06 \mathrm{~kg} \text { accounted for } 69,14 \%)\end{array}$} & \multicolumn{3}{|c|}{$\begin{array}{c}\text { Inorganic solid wastes } \\
(8,06 \mathrm{~kg} \text { accounted for } 30,86 \%)\end{array}$} \\
\hline & Compostion & Weight & $\%$ & Compostion & Weight & $\%$ \\
\hline 1 & Rice and leftovers & 5,51 & 21,09 & $\begin{array}{l}\text { Plastic cups and } \\
\text { wraps }\end{array}$ & 3,43 & 13,13 \\
\hline 2 & Vegetables & 5,55 & 21,25 & Plastic straws & 1,4 & 5,36 \\
\hline 3 & Fruit wastes & 4,07 & 15,58 & Nylon & 2,03 & 7,77 \\
\hline 4 & Leaves & 2,93 & 11,22 & Foam boxes & 1,2 & 4,59 \\
\hline
\end{tabular}

The results of the survey on average waste composition showed that organic solid waste accounted for $69 \%$, of which uneaten food $(21.09 \%)$; vegetables, fruits $(21.25 \%)$, leaves $(11.22 \%)$ and fruit peels $(15.58 \%)$. These types of solid wasteswere sourced from restaurants and partly from fast food stalls, which are easily biodegradable in nature, the decomposition process creating unpleasant odors especially in hot and humid weather. $31 \%$ of inorganic solid wastes includes plastic wrap, plastic cups, plastic straws, and foam boxes (Table 2).

Results of weighing and sorting wastes at the gathering place of tourist area, the amount of solid wastes generated for weekdays was approximate 70-100 kg/day and 200 - $300 \mathrm{~kg} /$ day for holidays and weekends. According to the calculated results, the rate of generation of solid wastes of the tourist area was approximate 0.3 $\mathrm{kg} /$ person/day. Compared to a study by the General Department of Environment (2008), the rate of generation of solid waste in the tourism area is lower, this may be due to the fact that visitors only stayed for short period of time (an average of 1 to 2 hours).

\subsection{Awareness of solid waste management of visitors at PhuHuu tourist site}

\subsubsection{Gender and age}

The interview results showed that the proportion of female accounted for 55\% (33/60 people), male accounted for $45 \%$ (27/60 people). The age of the respondents in PhuHuu tourist area between the ages of 18 to 30 years old accounts for $73.33 \%$ (44/60), the percentage of people aged 31 to 50 accounted for $23.33 \%$ (14/60), the proportion of people> 50 years old who took part in the interview was 2 people, accounting for $3.33 \%$. The above survey results showed that the people at ages of 18-30 years old tend to travel more than the other age groups.

\subsubsection{Education and occupation}

The majority of interviewers are qualified from high school and university. Visitors with high school level accounted for the highest proportion with $41 \%$, followed by the university level with $32 \%$. The number of people with college and intermediate degrees is relatively low, the proportion of colleges accounts for $20 \%$ and intermediate accounts for $7 \%$. The interview results showed that the educational level of the interviewees in the tourism area is relatively high.

In the tourist survey, visitors varied in occupations including office workers, business, housewives, workers, farmers and even students. Their main occupation is office workers accounting for $46.67 \%$, this is a job with relatively high pressure so most office workers tend to relax by traveling. For those who have a freelance business, the proportion of traveling is also relatively high at $23.33 \%$, with freelance work often not limited to working time, and high financial capacity. These are also people with relatively high qualifications, often traveling to many places, so they can also have an overview of life, including material and spiritual life, in which the spiritual life plays a part. The games in the tourist area are very important. Students also go on tours but this percentage is relatively low at only $13.33 \%$ which could be due to limited in financial capacity. Workers and farmers are the least traveled with workers only $6.67 \%$ and farmers $3.33 \%$; For workers, the rest time is relatively short except for big holidays. As for farmers, most of them are not limited by time but very few travelingand this could be because financial problem.

\subsubsection{Awareness of environmental protection of the tourists}

The awareness of environmental protection of the tourists in the study and the level of practice on environmental protection are also high. When asked how to use food (drinking water and fast food) at the counter or 
take away and after using the packaging, how the waste was handled and the results revealed that $100 \%$ of tourists put waste in the waste bins in accordance with the regulations. There were $100 \%$ of the tourists understood that it is harmful when indiscriminately discharging garbage into the environment. However, there were many different answers on the pollution of environmental compartments. For examples, 33.33\% of respondents said that waste would pollute soil, $18.33 \%$ said it would deteriorate water environment, $45 \%$ supposed it would destroy fresh air while $3.33 \%$ said it would pollute soil, water and air. The study also recored that $100 \%$ of the respondents totally agree that solid waste affects human health and causes diseases. There were $86.67 \%$ of interviewed visitors agree to pay the additional charge ranging from 1,000 to $2,000 \mathrm{VND}$ to the entry tickets for improving waste management systems. Regarding environmental management in the tourist area, $85 \%$ of tourists recommended to put extra waste bins in the tourist area.

\subsection{Current status of solid waste management in PhuHuu tourist area}

\subsection{Collection of solid waste}

According to the results of interviews with tourists about the collection and cleaning in the tourist area, up to $52 / 60$ people $(86.67 \%)$ said that they did not see the cleaning staff. In addition, over $80 \%$ of the respondents said that the placement of the waste bins and the size of the bins were not reasonable. However, according to the survey of solid waste management staff, it was said that there were many trash bins around the aisles in the tourist area in the past but the high amount of organic matters had created environmental problem, especially the bad odors from the waste bins. This led to the reduction of the waste bins. Since then the waste bins only installed at the drinks and fast food counters. Solid waste collection in the resort is arranged with five employees, with frequency 1 time/day. Everyday in the morning from 6 am to 9 am the whole tourist area is cleanedand all the solid wastes were collected and placed at the designed place. In addition, for food and drink counters with waste bins arranged at the point of sale, the owners of these saleswould be responsible for cleaning and managing the solid wastes.

\subsubsection{Current status of solid waste classification}

Classification is the important step in solid waste management. The purpose of solid waste classification is to separate the components according to their physical, chemical or biological characteristics to reuse, recycle or reprocessing. The survey results showed that the classification of solid waste at the tourist site has not been implemented, particularly in the tourist area, only one type of bin is installed for all types of wastes.

\subsubsection{Current status of solid waste storage}

After being collected, solid wastes were transported to the stockpile in the tourist site. The storage is arranged by the Tourism Management Board at the area away from the sightseeing and dining areas, with an area of about $2 \mathrm{~m}^{2}$. At the storage site, solid waste is stored in the 10 containers with dimensions of $\varnothing 600$ x H $470 \mathrm{~mm}$. The survey revealed that the storage of solid waste in the tourist area is not hygienic, in particular the containers do not have lids, creating an unpleasant odor. Odors are formed because solid waste is stored for long, creating a special odor that increases sharply on high temperature days, due to anaerobic decomposition of organic matters.

\subsubsection{Current status of solid waste transport and treatment}

Through interviews with officials and employees of the Tourism Management Board, the tourist area has signed a contract with the Water Supply and Sewerage Joint Stock Company - Hau Giang Urban Works, Chau Thanh Branch to collect and treat solid wastes. The company is responsible for collection of the wastes at the gathering point of the tourist area so the collection rate reaches $100 \%$, with the frequency of collection is once a day in the time frame from 17:30 to 18:00.

\subsection{Evaluation of solid waste management}

The issue of environmental sanitation at the tourist site has been concerned by the Tourism Management Board and is fully aware of the importance of environmental protection. In the study area, solid waste collection has been carried out; However, it is only carried out at a good level with the frequency of collection is not high and not reasonable. Besides, the arrangement of less waste bins also affects the collection since a few tourists could throw wastes indiscriminately. The classification of solid waste in the tourist area has not been implemented, only one type of waste bin is allocated to all types of wastes. Regarding the storage of solid waste at the stockpile area, although there has been a land area as well as the containers to store wastes, this storage area has not been hygienic because the containers do not have lids which could result in generating bad odors.

\subsection{Proposing solutions for solid waste management in Phu Huu tourist area}

In order to better management of solid wastes at the study site, the managers should improve the organization of collection and sanitation by the allocation of more staff for increasing the frequency of cleaning. In addition, the 
managers should minimize by imposing extra charge for the food and items brought in from outside. Promoting the propaganda, education to raise awareness and responsibility of environmental protection of the visitor community is necessary. Diversify the forms of propaganda and dissemination of tourism regulations to officials, employees and tourists regarding solid waste management is urgently needed.

Furthermore, the solid waste generated in the tourism area should be sorted at source, possibly based on the $3 \mathrm{R}$ principle (reduce, reuse and recycle). For organic solid waste that has leftovers, spoiled vegetables can be put in a covered container and then given to surrounding households as pet food, which can minimize the amount of organic solid waste generated in tourist areas, limiting odors. For plastic cups and plastic bottles, the users should pay for extra cost included in the tickets so the amount of the wastes could be efficiently reduced.

\section{CONCLUSION}

The results of solid waste analysis in the tourist area showed that the amount of waste generated was 70-100 $\mathrm{kg}$ /day on weekdays and 200-300 kg/day for weekends/holidays. The rate of generation of solid waste in the tourist area averaged at $0.3 \mathrm{~kg} /$ person/day. Through practical surveys and analysis, the solid waste composition in the study area includedtwo types of inorganic wastes accounting for $31 \%$ comprising plastic wrap, plastic cups, plastic straws, foam boxes and organic waste occupied $69 \%$ including leftovers, vegetables, fruits, leaves, fruit peels. Current situation of solid waste management in tourism area was limited showing through the waste is not classified, waste bins and its size were not appropriate; the waste bins were not covered. The managers of the tourism area need need to fix all the existing problems including allocation of more staff working on solid waste collection, waste separation, and allocation of more waste bins with the appropriate covers. Extra fees should be charged on the food and stuff taken from outside, and plastic stuffs. Raising the awareness of environmental protection for visitors and staffs in the tourist area is essential.

\section{REFERENCES}

[1] Bui Huu Long and Phi Phuong Mai (2013). Assess the impact of ecotourism development on environmental components at My Le Ecological Tourism Area. Ho Chi Minh City University of Agriculture and Forestry.

[2] Jindal, R., Harada and Shikura, S. (1998). Solid waste management in several Asian countries. Review of environmental systems 42/43. Bangkok, Thailand:
Information Center on Environmental Systems (ENVSIC), Asian Institute of Technology.

[3] Le Hoang Viet, Nguyen Huu Chiem (2013), Curriculum on solid waste management and treatment. Can Tho University Publishing House.

[4] Suarnatha, I.M. (1990). Hotel solid waste management. Case study of alternative model of Jimbarau, Bali, Indonesia.

[5] General Department of Environmental Protection (2008). Project of Modeling and pilot implementation of classification, collection and treatment of daily-life waste for new urban areas.

[6] Tran Hieu Nhue and Nguyen Quoc Cong (2005). Research and study on organic waste management of Bai Chay tourist area, Tp. Ha Long. Culture and Information Publishing House, Hanoi.

[7] Tran Thi Huong (2018). Assessing the impact of ecotourism activities on the natural and social environment in Ban Lac, Chieng Chau commune, Mai Chau district, Hoa Binh province. Journal of Forestry Science and Technology.

[8] Tran Thi My Dieu, Le Minh Truong and Nguyen Trung Viet (2013). Composition, volume of domestic solid waste from households and the ability to recover and recycle: Case study in District 1, Ho Chi Minh City Chi Minh. 